Polymer Journal, Vol. 38, No. 9, pp. 920-929 (2006)

(C) 2006 The Society of Polymer Science, Japan

\title{
Properties and Crystallization of Maleated Polypropylene/Graphite Flake Nanocomposites
}

\author{
Danny J. Y. S. PAGÉ ${ }^{1, \dagger}$ and Thottupurathu G. GOPAKUMAR ${ }^{2}$ \\ ${ }^{1}$ Department of Chemistry and Chemical Engineering, Royal Military College of Canada, \\ Kingston, Ontario, Canada K7K $7 B 4$ \\ ${ }^{2}$ General Electric Energy, Lees Summit, MO 64082, United States
}

(Received May 1, 2006; Accepted June 2, 2006; Published July 28, 2006)

\begin{abstract}
Polypropylene (PP)/graphite $(\mathrm{G})$ hybrid nanocomposites have been prepared by melt mixing using maleated PP (PP-g-MA) and graphite oxide (GO) as compatibilizing agents. Melt mixing was achieved using a Gelimat, a high-speed thermo-kinetic mixer. The PP-g-MA and GO used as compatibilizers helped the dispersion of the graphite on a nano-scale and improved flexural properties but more significantly the impact strength of the material. TEM micrographs showed a partial exfoliation of the graphite in the PP/PP-g-MA/GO/G hybrid nanocomposites. SEM micrographs of etched nanocomposite samples showed a fine grain micron-sized structure, while pure PP was characterized by larger 3-dimensional spherulites. Non-isothermal crystallization kinetics of PP and PP/PP-g-MA/ $\mathrm{GO} / \mathrm{G}$ nanocomposites were investigated by differential scanning calorimetry (DSC). The crystallinity and crystallization temperature of the nanocomposites were higher than for neat PP. Using the Kissinger model, the activation energy of crystallization of the nanocomposites was determined to be lower than PP. Models by Ozawa and Liu et al. were used to analyze and describe the non-isothermal crystallization kinetics. Overall, results indicate that the type of nucleation, growth and geometry of PP crystals markedly change in the presence of nano-sized graphite particles.

[doi:10.1295/polymj.PJ2006020]

KEY WORDS nanocomposites / polypropylene / graphite / non-isothermal / crystallization kinetics /
\end{abstract}

The dispersion of nanoscopic fillers in commodity resins is one of the latest evolutionary steps of polymer technology. ${ }^{1-6}$ Nanofillers most often used are clay, alumina, nanotubes, gold, silver and various forms of carbon compounds including graphite $(\mathrm{G}) .{ }^{1}$ Preparation and characterization of polymer nanocomposites based on polypropylene (PP) and montmorillonite type clay have been extensively reported. ${ }^{7-11}$ Interest in polyolefin nanocomposites has emerged due to their promise of improved performance in packaging and engineering applications. Chemical modification of these resins, in particular the grafting of pendant anhydride groups, has been used successfully to overcome problems associated with poor phase adhesion in polyolefin/clay systems. ${ }^{7,8}$

More recently, polymer/graphite nanocomposites have raised some interest due to their potential conductive properties. ${ }^{12-18}$ The weak interplanar forces allow the possibility for certain atoms, molecules and ions to intercalate into the interplanar spaces of the graphite aggregates. The interplanar spacings, also called galleries, could then be increased. However, non-polar PP does not interact with chemically inert graphite flakes and therefore producing PP/G nanocomposites is very difficult. ${ }^{12,13}$ The ion exchange reactions, used to intercalate polymers between smectite clay platelets, ${ }^{1-11}$ are not possible in inert graphite.
Recently, the authors successfully used graphite oxide (GO) and maleic anhydride grafted PP (PP-g-MA) to improve the interfacial adhesion between the graphite phase and PP phase. ${ }^{18}$

Generally, the preparation of nanocomposites by melt blending is performed either with a batch mixer $^{2-4}$ or an extruder. ${ }^{1-7}$ In a Gelimat, blades on a high-speed shaft accelerate the particles and impart them high kinetic energy, which is converted to thermal energy when they hit the chamber wall. ${ }^{19}$ The compounding time is generally within a few minutes and depends on the charge size, the rotor speed as well as the properties of the material. ${ }^{20}$ The high shear rates developed by the Gelimat makes it a good tool for the compounding of nanocomposites. ${ }^{21}$

The study of the kinetics of crystallization is necessary for optimizing industrial process conditions and establishing the structure-property correlations in polymer nanocomposites. ${ }^{22}$ The study of the non-isothermal crystallization of polymers is of great technical significance, since most practical processing techniques proceed under non-isothermal conditions. ${ }^{22-24}$ The isothermal and non-isothermal crystallization kinetics of PP and PP/clay have been reported in the literature. ${ }^{25-34} \mathrm{Xu}$ et $a .^{29}$ studied the non-isothermal crystallization kinetics of $\mathrm{PP} /$ montmorilloniteclay nanocomposites and found that clay could accel-

${ }^{\dagger}$ To whom correspondence should be addressed (Tel: 1-613-541-6000 ext.6353; Fax: 1-613-542-9489, E-mail: page-d@ rmc.ca). 
erate the overall non-isothermal crystallization of PP. $\mathrm{Xu}$ et al. ${ }^{29}$ suggested a three-dimensional growth with heterogeneous nucleation for $\mathrm{PP} /$ clay nanocomposites. Maiti et al..$^{26}$ investigated how the crystallization controls the fine structure and morphology of the PP/ clay nanocomposites. They have concluded that the clay platelets act as a nucleating agent and lower the size of the PP spherulites. Qian ${ }^{27}$ successfully used models by Ozawa and Liu et al. to describe the nonisothermal crystallization of $\mathrm{PP} /$ nano- $\mathrm{SiO}_{2}$ composites and reported an increase of a few degrees of the crystallization temperature. He et al. ${ }^{28}$ reported an increase of $5^{\circ} \mathrm{C}$ in the crystallization temperature of PP in the presence of nano-clay.

The crystallization behavior of PP is also affected by carbon black ${ }^{35}$ and carbon nanotubes. ${ }^{36-39}$ Mucha et al. reported a PP crystallization temperature increase of $8{ }^{\circ} \mathrm{C}$ with the addition of $5 \%$ carbon black. ${ }^{35}$ Grady et al. reported a PP crystallization temperature increased of $5{ }^{\circ} \mathrm{C}$ with the addition of $1.8 \%$ carbon nanotubes while the crystallinity did not change under non-isothermal cooling conditions. ${ }^{36}$ Valentini et al. reported a $13{ }^{\circ} \mathrm{C}$ increase with $5 \%$ carbon nanotubes. ${ }^{38}$ In another case, although the PP crystallization temperature increased by $5{ }^{\circ} \mathrm{C}$, a $5 \%$ reduction in crystallinity was measured in the presence of $1 \%$ carbon nanotubes. ${ }^{39}$ Overall, carbon compounds increased more significantly the crystallization temperature of PP than clay or $\mathrm{SiO}_{2}$.

The work presented in this paper is the first to investigate the effect of graphite particles, which are structurally different than carbon black or nanotubes, on the non-isothermal crystallization behavior of $\mathrm{PP}$ in $\mathrm{PP} / \mathrm{G}$ nanocomposites. Models by Kissinger, Ozawa and Liu et al. were used to describe the nonisothermal crystallization behavior of the PP and nanocomposites.

\section{EXPERIMENTAL}

\section{Materials}

Polypropylene (PP MFI $=4$, Basell Chemicals) and graft-modified PP containing approximately $1 \mathrm{wt} \%$ of maleic anhydride (PP-g-MA, Uniroyal) were used without purification. Commercially available natural graphite flakes (NGF) (dimension $50 \mu \mathrm{m} \times 3 \mathrm{~mm}$ ) were used as received. Some graphite flakes were chemically modified to graphite oxide (GO) using a concentrated acid solution by the procedure described in the literature. ${ }^{15,18}$

\section{Composite Preparation}

A Gelimat thermo-kinetic mixer (a high intensity turbine mixer Werner-Pfledere G-1) was used to produce nanocomposites in $250 \mathrm{~g}$ batches. The Gelimat was operated at a speed of $2000 \mathrm{rpm}$ for mixing times of $70-220 \mathrm{~s}$ and a final mixing temperature of $190^{\circ} \mathrm{C}$.

\section{Mechanical Properties}

Flexural strength and modulus were measured by a three-point flexural test on a Universal Tensile Tester (Instron 4206) with a crosshead speed of $5 \mathrm{~mm} / \mathrm{min}$ at room temperature according to ASTM D638. Test specimens for flexural $(110 \times 25 \times 3.2 \mathrm{~mm})$ and impact $(64 \times 12.7 \times 3.2 \mathrm{~mm})$ strength measurements were machined out from sheets produced by compression molding. Notched Izod impact strength was measured according to ASTM D256. Each data point is based on at least five measurements per composite.

\section{Morphology Characterization}

Thin sections $(70 \mathrm{~nm})$ were cut on a Leica Ultracut at $-100^{\circ} \mathrm{C}$ and mounted on carbon coated copper grids. The samples were viewed in a FEI Tecnai 20 transmission electron microscope (TEM) at $200 \mathrm{kV}$. Images were collected on a Gatan Dualview digital camera. A scanning electron microscope (SEM) (Philips, USA) was used to observe the crystalline morphology of pure PP and PP matrix in the presence of graphite. Samples were prepared by fracturing specimens in liquid nitrogen. A mixture of potassium permanganate $\left(\mathrm{KMnO}_{4}\right)$, concentrated sulfuric acid $\left(\mathrm{H}_{2} \mathrm{SO}_{4}\right)$ and phosphoric acid $\left(\mathrm{H}_{3} \mathrm{PO}_{4}\right)$ was used to remove the amorphous part of the PP in order to observe the PP crystallites. ${ }^{40}$ An ideal mixture consists of $7 \mathrm{wt} \% \mathrm{KMnO}_{4}$ in 2:1 $\mathrm{H}_{2} \mathrm{SO}_{4} / \mathrm{H}_{3} \mathrm{PO}_{4}$. All samples were coated with gold.

\section{Crystallization Behavior}

Crystallization properties were studied by using a Seiko series Differential Scanning Calorimeter (DSC). Samples were heated from $50^{\circ} \mathrm{C}$ to $180^{\circ} \mathrm{C}$ at a rate of $10^{\circ} \mathrm{C} /$ min under a nitrogen atmosphere and held for $10 \mathrm{~min}$ to destroy any residual nuclei before cooling at the desired rate $\left(2.5,5,10\right.$, and $\left.20^{\circ} \mathrm{C} / \mathrm{min}\right)$. The degree of crystallinity $\left(X_{c}\right)$, corrected for graphite content was determined by integration of the DSC exotherm, from which the relative crystallinity $\left(X_{T}\right)$ could be calculated as a function of temperature. ${ }^{11,12}$

\section{RESULTS AND DISCUSSION}

\section{Mechanical Properties}

Figures 1 and 2 show the effect of graphite content on the flexural modulus and strength of $\mathrm{PP} / \mathrm{G}(5 \%)$ composites and PP/PP-g-MA(5\%)/GO(1\%)/G(4\%) nanocomposites. The presence of the rigid graphite increased the modulus and flexural strength in both $\mathrm{PP} / \mathrm{PP}-\mathrm{g}-\mathrm{MA} / \mathrm{GO} / \mathrm{G}$ and $\mathrm{PP} / \mathrm{G}$ over neat PP. The increase in modulus $(+50 \%)$ and strength $(+25 \%)$ 


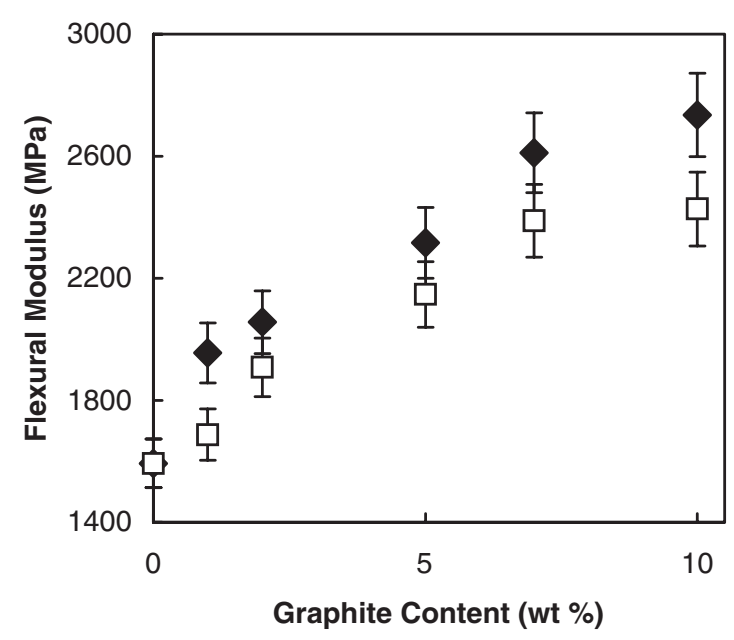

Figure 1. Flexural modulus as function of graphite content for the $(\square) \mathrm{PP} / \mathrm{G}(5)$ and $(\diamond) \mathrm{PP} / \mathrm{PP}-\mathrm{g}-\mathrm{MA}(5) / \mathrm{GO}(1) / \mathrm{G}(4)$ composites.

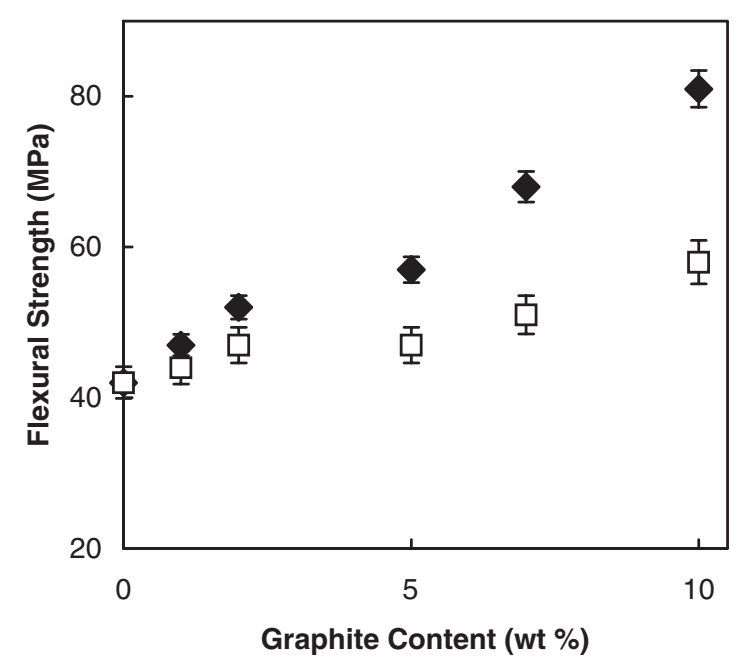

Figure 2. Flexural strength as function of graphite content for the $(\square) \mathrm{PP} / \mathrm{G}(5)$ and $(\bullet) \mathrm{PP} / \mathrm{PP}-\mathrm{g}-\mathrm{MA}(5) / \mathrm{GO}(1) / \mathrm{G}(4)$ composites.

due to the addition of PP-g-MA/GO/G in PP were higher than for comparable increases (respectively $+17 \%$ and $+7 \%$ ) for HDPE composites prepared with expandable graphite given a similar loading level of $3 \% .{ }^{17}$ The improved properties were attributed to a better exfoliation and dispersion of the graphite aggregates, as previously reported from XRD results. ${ }^{18}$ The presence of PP-g-MA and GO promoted physical interactions between graphite and PP chains during the intensive mixing of the Gelimat, resulting in high shear stress and a better dispersion of the graphite in the PP matrix.

Figure 3 shows that the Notched Izod impact strength of $\mathrm{PP} / \mathrm{G}$ nanocomposites increased with graphite content in the presence of PP-g-MA and GO as compatibilizers. The use of PP-g-MA and GO is re-

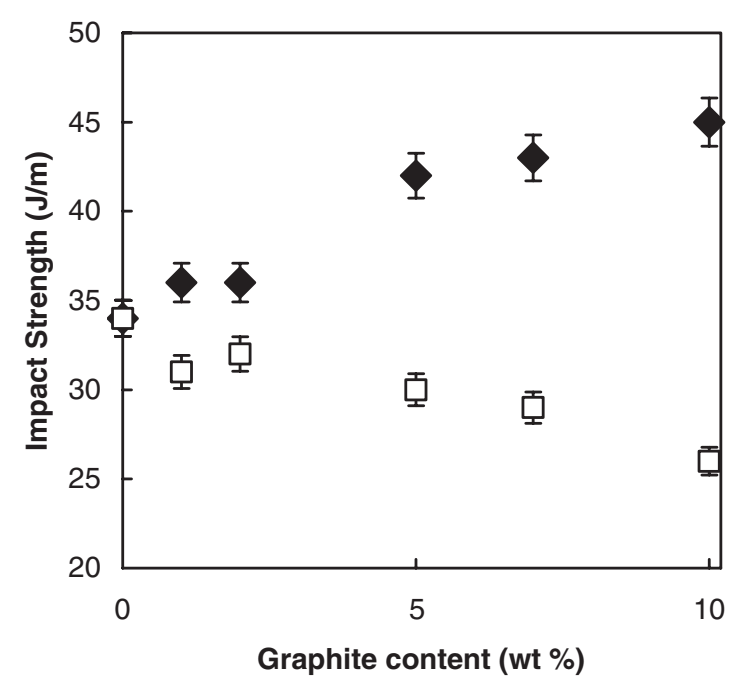

Figure 3. Impact strength as function of graphite content for the $(\square) \mathrm{PP} / \mathrm{G}(5)$ and $(\bullet) \mathrm{PP} / \mathrm{PP}-\mathrm{g}-\mathrm{MA}(5) / \mathrm{GO}(1) / \mathrm{G}(4)$ composites.

sponsible for a better dispersion of the reinforcement and a stronger bonding interface with the resin. The observed improvement in impact strength is also consistent with the reduction of spherulite size in $\mathrm{PP} / \mathrm{PP}-$ g-MA/GO/G nanocomposites. The more brittle nature of neat PP is attributed to the larger 3D spherulites as discussed in the following section.

\section{Morphology Characterization}

$\mathrm{PP} / \mathrm{PP}-\mathrm{g}-\mathrm{MA} / \mathrm{GO} / \mathrm{G}$ nanocomposites were characterized by scanning (SEM) and transmission electron microscopy (TEM). The observed partial exfoliation is consistent with the dispersion in hybrid nanocomposites.

Figure 4a shows the SEM image of natural graphite flakes (NGF). The NGF has a thickness of $50-100 \mu \mathrm{m}$ and a lateral dimension of about $3 \mathrm{~mm}$. Figure $4 \mathrm{~b}$ shows the TEM images of PP/PP-g-MA/GO/G nanocomposites with reference bars of $0.2 \mu \mathrm{m}$ and $0.5 \mu \mathrm{m}$ respectively. The dark regions in the TEM images are indicative of the width of the partially exfoliated graphite sheets while black lines are more indicative of the thickness of those aggregates of sheets. This result is consistent with X-ray diffraction study of PP/ PP-g-MA/GO/G nanocomposites reported previously. ${ }^{18}$ The addition of GO and PP-g-MA improves the interfacial adhesion between the graphite phase and the polymer phase and is responsible for the NGF breakage into submicron particles and the dispersion within the PP matrix under the Gelimat high shear rates. In contrast, some NGF fragments were still visible to the naked eye when mixed only with neat PP.

The Figures 5a, 5b and 5c show the crystalline morphology of pure PP and PP matrix in nanocomposites with bar scales of $20 \mu \mathrm{m}$ and $2 \mu \mathrm{m}$ respectively. In 

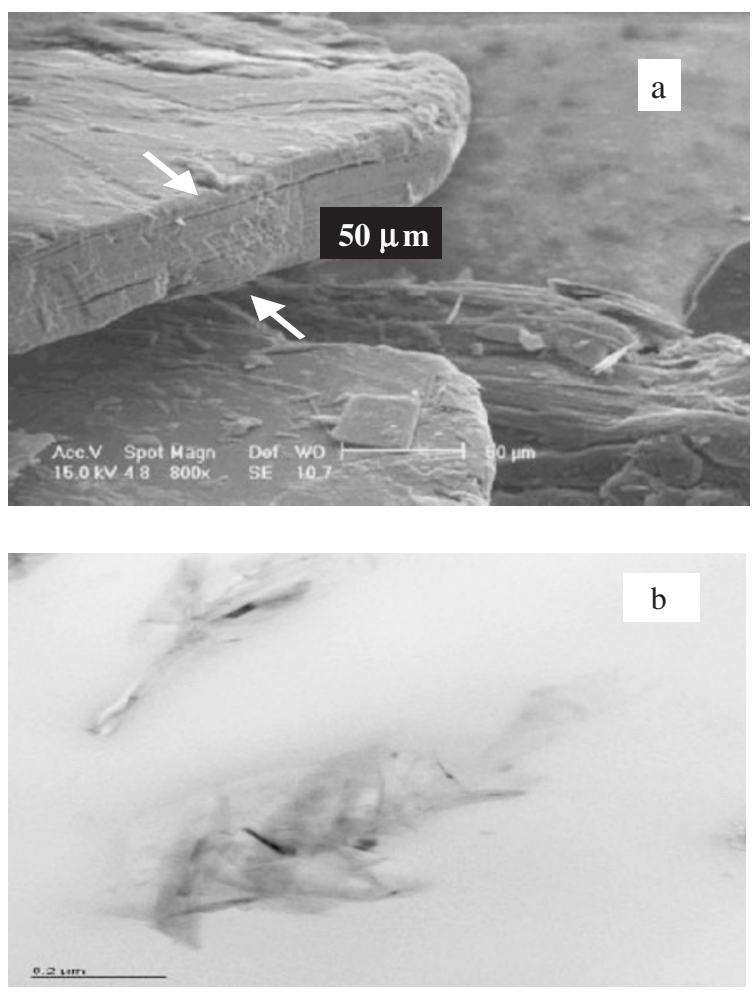

Figure 4. (a) SEM images of natural graphite flakes as received, (b) TEM image of PP/PP-g-MA(5)/GO(1)/G(4) nanocomposites (scale bar $=0.2 \mu \mathrm{m}$ ).

Figure 5a, pure PP is characterized by a $20-30 \mu \mathrm{m} 3-$ dimensional spherulite morphology. In Figure 5b, this spherulite morphology is absent from the nanocomposites. Instead, Figure 5c shows much smaller micronsized crystallites. This clearly indicates that the graphite particle act as nucleating agent for PP and modifies the geometry of the crystals through an heterogeneous nucleation.

\section{Crystallization Behavior}

The crystallization behavior of PP and PP nanocomposites with graphite content was studied at cooling rates $(\varphi)$ between 2.5 and $20^{\circ} \mathrm{C} / \mathrm{min}$. Non-isothermal crystallization thermograms of PP and PP/PP-g$\mathrm{MA} / \mathrm{GO} / \mathrm{G}$ at different cooling rates are shown in Figures $6 \mathrm{a}$ and $6 \mathrm{~b}$. The crystallization temperature $\left(T_{c}\right)$ and the percent crystallinity $\left(X_{c}\right)$ of the PP phase are presented in Table I. The crystallization temperatures are those corresponding to the exothermic peak maxima $\left(T_{p}\right)$ as described by Elder and Wlochowicz. ${ }^{41}$ The enthalpy of crystallization $\left(\Delta H_{c}\right)$ has been calculated from the enthalpy of crystallization normalized to the PP content, assuming that the thermodynamic contribution of the graphite phase is negligible. The percent crystallinity of pure PP and the PP matrix in the nanocomposites was determined by eq 1 where the value of the heat of crystallinity of pure crystalline $\mathrm{PP}\left(\Delta H_{c}^{0}\right)$ was assumed to be $146.5 \mathrm{~J} / \mathrm{g} .{ }^{41}$
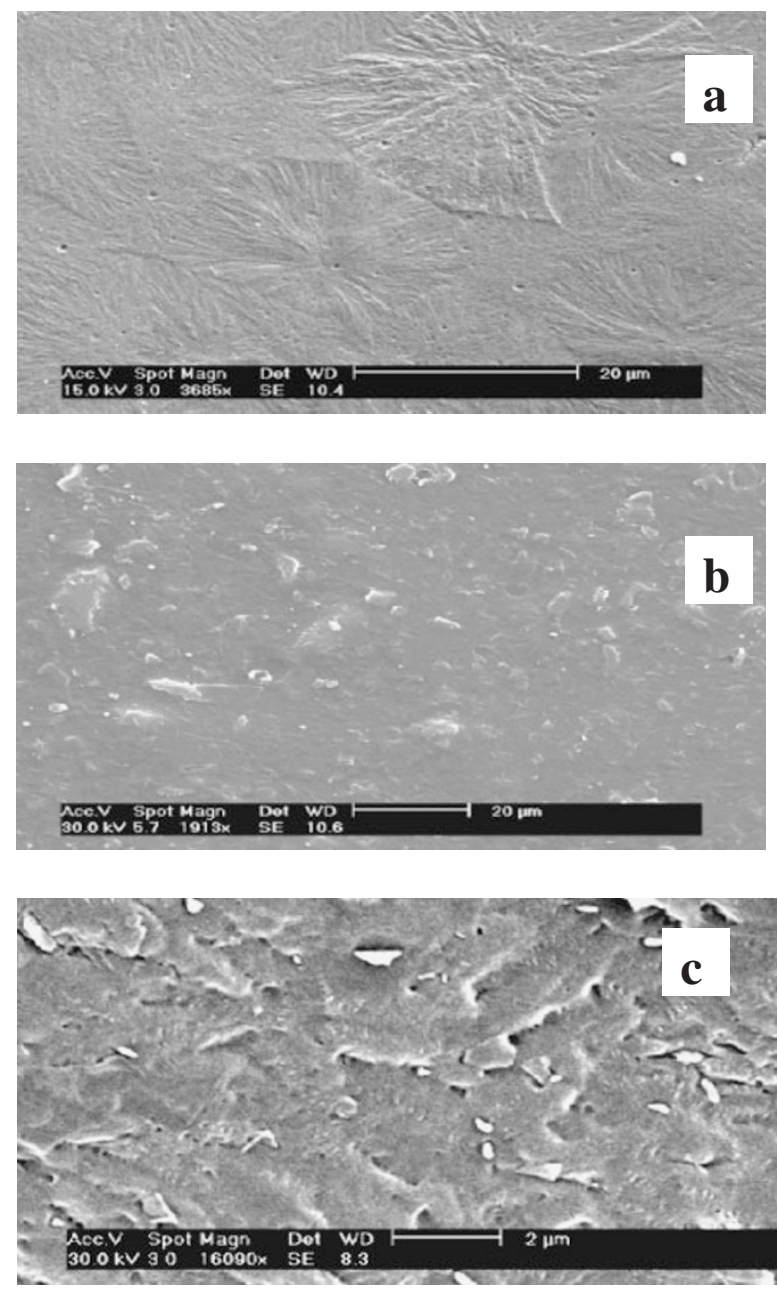

Figure 5. (a) SEM images of (a) pure PP showing spherulite morphology (Amorphous phase of PP with etched with $\mathrm{KMnO}_{4}$ / $\mathrm{H}_{2} \mathrm{SO}_{4} / \mathrm{H}_{3} \mathrm{PO}_{4}$ mixture, scale bar $=20 \mu \mathrm{m}$ ), (b) PP/PP-g$\mathrm{MA}(5) / \mathrm{GO}(1) / \mathrm{G}(4)$ nanocomposites, scale bar $=20 \mu \mathrm{m}),(\mathrm{c}) \mathrm{PP} /$ PP-g-MA(5)/GO(1)/G(4) nanocomposites showing crystalline morphology (scale bar $=2 \mu \mathrm{m})$.

$$
X_{c}=\frac{\Delta H_{c}}{\Delta H_{c}^{0}} \times 100
$$

The crystallization temperature of PP generally increased by $15^{\circ} \mathrm{C}$ in the presence of graphite (Figures $6 \mathrm{a}, 6 \mathrm{~b}$ and Table I) whereas it decreased when the cooling rate was increased, as could be expected for polymer crystallization in the presence of a nucleating agent. ${ }^{23}$ Furthermore, the crystallinity also increased with the presence of graphite but more significantly with the presence of the GO and PP-g-MA as compatibilizing agents.

The crystallization temperature from Table I were used to calculate the crystallization activation energy $(\Delta E)$ with a model proposed by Kissinger ${ }^{42}$ shown as eq 2:

$$
-\Delta E / R=d\left[\ln \left(\varphi T_{p}^{2}\right)\right] / d\left(T_{p}^{-1}\right)
$$

The crystallization activation energy $(\Delta E)$ is deter- 


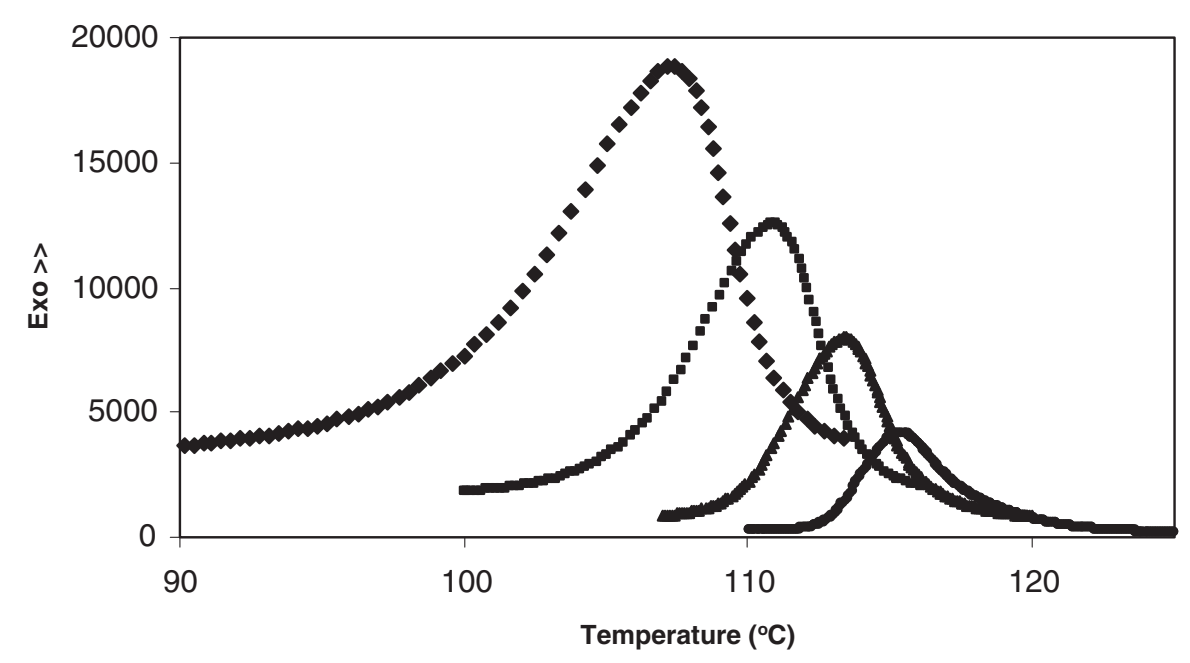

(a)

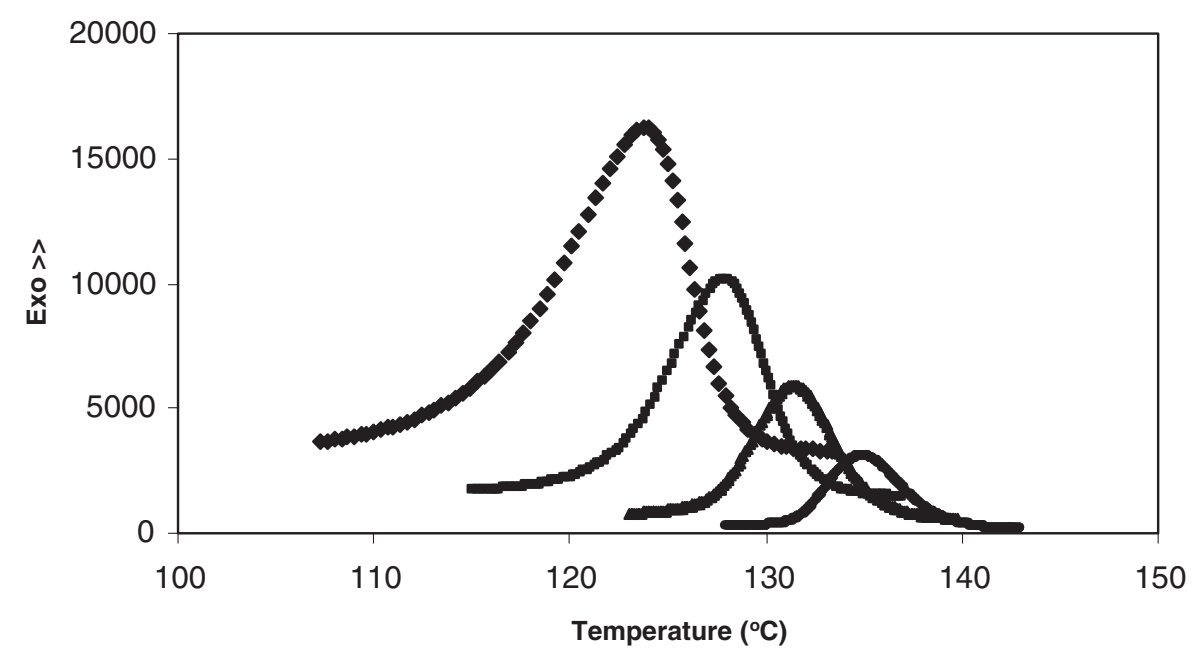

(b)

Figure 6. Non-isothermal crystallization thermograms of (a) PP and (b) PP/PP-g-MA(5)/GO(1)/G(4) nanocomposites at different cooling rates: $(\diamond) 20^{\circ} \mathrm{C} / \min (\square) 10^{\circ} \mathrm{C} / \min (\Delta) 5^{\circ} \mathrm{C} / \min (\bullet) 2.5^{\circ} \mathrm{C} / \mathrm{min}$.

Table I. Crystallization temperature and maximum percent crystallinity of PP/nanocomposites for cooling rates of $2.5,5,10$ and $20^{\circ} \mathrm{C} / \mathrm{min}$

\begin{tabular}{lcccccccc}
\hline Nanocomposite $(\mathrm{wt} \%)$ & \multicolumn{2}{c}{$2.5^{\circ} \mathrm{C} / \mathrm{min}$} & \multicolumn{2}{c}{$5{ }^{\circ} \mathrm{C} / \mathrm{min}$} & \multicolumn{2}{c}{$10^{\circ} \mathrm{C} / \mathrm{min}$} & \multicolumn{2}{c}{$2{ }^{\circ} \mathrm{C} / \mathrm{min}$} \\
\hline & $T_{c}$ & $X_{c}$ & $T_{c}$ & $X_{c}$ & $T_{c}$ & $X_{c}$ & $T_{c}$ & $X_{c}$ \\
& $\left({ }^{\circ} \mathrm{C}\right)$ & $\%$ & $\left({ }^{\circ} \mathrm{C}\right)$ & $\%$ & $\left({ }^{\circ} \mathrm{C}\right)$ & $\%$ & $\left({ }^{\circ} \mathrm{C}\right)$ & $\%$ \\
\hline $\mathrm{PP}$ & 115 & 54 & 113 & 52 & 111 & 53 & 107 & 49 \\
$\mathrm{PP} / \mathrm{G}(5)$ & 133 & 58 & 130 & 55 & 129 & 55 & 122 & 52 \\
$\mathrm{PP} / \mathrm{PP}-\mathrm{g}-\mathrm{MA}(5) / \mathrm{GO}(1) / \mathrm{G}(1)$ & 134 & 72 & 131 & 70 & 129 & 69 & 123 & 67 \\
$\mathrm{PP} / \mathrm{PP}-\mathrm{g}-\mathrm{MA}(5) / \mathrm{GO}(1) / \mathrm{G}(4)$ & 135 & 71 & 132 & 72 & 129 & 69 & 123 & 70 \\
$\mathrm{PP} / \mathrm{PP}-\mathrm{g}-\mathrm{MA}(5) / \mathrm{GO}(1) / \mathrm{G}(6)$ & 135 & 69 & 133 & 70 & 131 & 64 & 124 & 67 \\
$\mathrm{PP} / \mathrm{PP}-\mathrm{g}-\mathrm{MA}(5) / \mathrm{GO}(1) / \mathrm{G}(9)$ & 136 & 67 & 131 & 67 & 130 & 65 & 122 & 68 \\
\hline
\end{tabular}

mined by plotting $\ln \left(\varphi T_{p}^{2}\right)$ against $T_{p}^{-1}$ and multiplying the slope by the universal gas constant $(R)$. The $\Delta E$ values calculated from Figure 7 are 321, 247 and $237 \mathrm{KJ} \mathrm{mol}^{-1}$ respectively for $\mathrm{PP}, \mathrm{PP} / \mathrm{G}(5)$ and $\mathrm{PP} / \mathrm{PP}-\mathrm{g}-\mathrm{MA}(5) / \mathrm{GO}(1) / \mathrm{G}(4)$. Lower crystallization $\Delta E$ values are consistent with the higher crystallinity values found in Table I and indicates that the non-isothermal crystallization of PP is facilitated and increased appreciably by the presence of graphite and even more with the addition GO and PP-g-MA as compatibilizing agents.

Crystallization as a function of temperature can be 


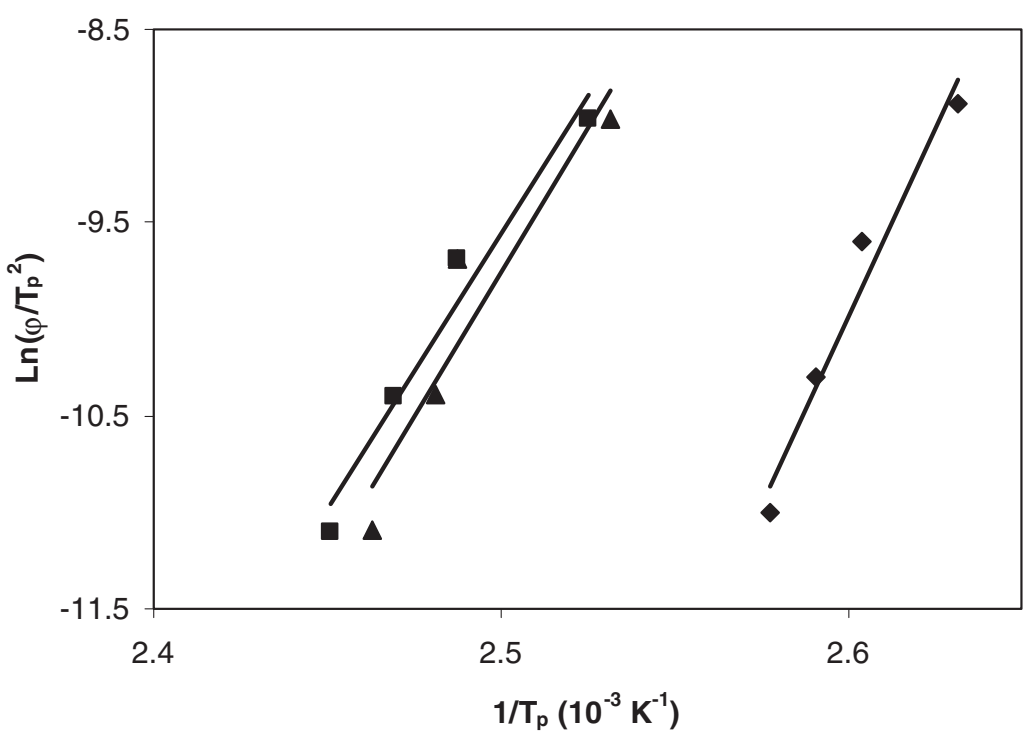

Figure 7. Kissinger model plots to determine the crystallization activation energy. Slope multiplied by the universal gas constant $(R)$ yields a $\Delta E$ value of $321 \mathrm{KJ} \mathrm{mol}^{-1}$ for $\mathrm{PP}(\bullet), 247 \mathrm{KJ} \mathrm{mol}^{-1}$ for $\mathrm{PP} / \mathrm{G}(5)(\boldsymbol{\Delta})$ and $237 \mathrm{KJ} \mathrm{mol}^{-1}$ for PP/PP-g-MA(5)/GO(1)/G(4) (匹).

Table II. Non-isothermal crystallization $T_{\mathrm{o}}, t_{p}$ and $t_{1 / 2}$ for PP and nanocomposites

\begin{tabular}{lccrrr}
\hline Composition $(\%)$ & $\varphi\left({ }^{\circ} \mathrm{C} / \mathrm{min}\right)$ & $T_{p}\left({ }^{\circ} \mathrm{C}\right)$ & $t_{p}(\mathrm{~s})$ & $T_{\mathrm{o}}\left({ }^{\circ} \mathrm{C}\right)$ & $t_{1 / 2}(\mathrm{~s})$ \\
\hline $\mathrm{PP}$ & 2.5 & 115 & 202 & 124 & 152 \\
& 5 & 113 & 71 & 119 & 69 \\
& 10 & 111 & 40 & 117 & 49 \\
& 20 & 107 & 26 & 116 & 43 \\
\hline $\mathrm{PP} / \mathrm{PP}-\mathrm{g}-\mathrm{MA}(5) /$ & 2.5 & 135 & 167 & 142 & 155 \\
$\mathrm{GO}(1) / \mathrm{G}(4)$ & 5 & 132 & 86 & 138 & 87 \\
& 10 & 129 & 44 & 135 & 55 \\
& 20 & 123 & 21 & 132 & 33 \\
\hline
\end{tabular}

transposed onto a time scale by using the relationship $t=\left(T_{0}-T\right) / \varphi$ (where $T_{0}$ is the onset temperature at a crystallization time of $t=0$, and $T$, the temperature at a crystallization time $t) .{ }^{6,25-29}$ The onset and end of crystallization for time and temperature were taken respectively at $0.1 \%$ and $99.9 \%$ relative crystallinity. The crystallization time $\left(t_{p}\right)$ is defined as the period from the onset of crystallization time at $t=0$ to the time corresponding to the peak crystallization temperature $T_{c}{ }^{26}$ The half crystallization time $\left(t_{1 / 2}\right)$ is defined as the half period from the onset of crystallization and the end of crystallization. $t_{p}$ and $t_{1 / 2}$ values are summarized in Table II and are comparable for PP nanocomposites and PP although the onset of crystallization is $15-19^{\circ} \mathrm{C}$ higher for the PP nanocomposites. In comparing those crystallization times, one must keep in mind that the absolute crystallinity reported in Table I is higher for the nanocomposite and that crystallization occurs at higher $T$. Therefore PP crystals nucleate easier and grow at a faster rate in the nanocomposite.

Overall it can be concluded that the type of nucle- ation, growth and geometry of crystals markedly change in the presence of dispersed graphite particles with thicknesses in the nano-scale.

\section{Crystallization Kinetics Modelling}

Resin crystallization, with and without reinforcement, can be further analyzed by applying existing kinetic models. The Avrami model, ${ }^{43}$ shown below, is well known and widely used. This model was originally developed for the isothermal crystallization of metals:

$$
X_{t}=\left(1-\exp \left(-k t^{n}\right)\right.
$$

In eq $3, X_{t}$ is the relative degree of crystallinity, $k$ is a kinetic constant involving both nucleation and growth rate parameters and $n$ is the Avrami exponent, dependent on the type of nucleation and growth process parameters. Eq 3 can be lineralized in its double logarithmic form to give eq 4 .

$$
\ln \left[-\ln \left(1-X_{t}\right)\right]=\ln k+n \ln t
$$

While eq 4 was developed to describe isothermal crystallization kinetics, it has also been used in a less conventional way to describe non-isothermal crystallization kinetics. ${ }^{23,25,29}$ In that case, the model parameters $n$ and $k$ take on a different meaning given the temperature gradient applied during testing.

Assuming that a non-isothermal crystallization process is the result of infinitely small changes in isothermal crystallization steps, Ozawa ${ }^{44}$ modified the Avrami model to the form:

$$
1-X_{T}=\exp \left(-\chi / \varphi^{m}\right)
$$

which can be expressed in a double logarithmic form as: 


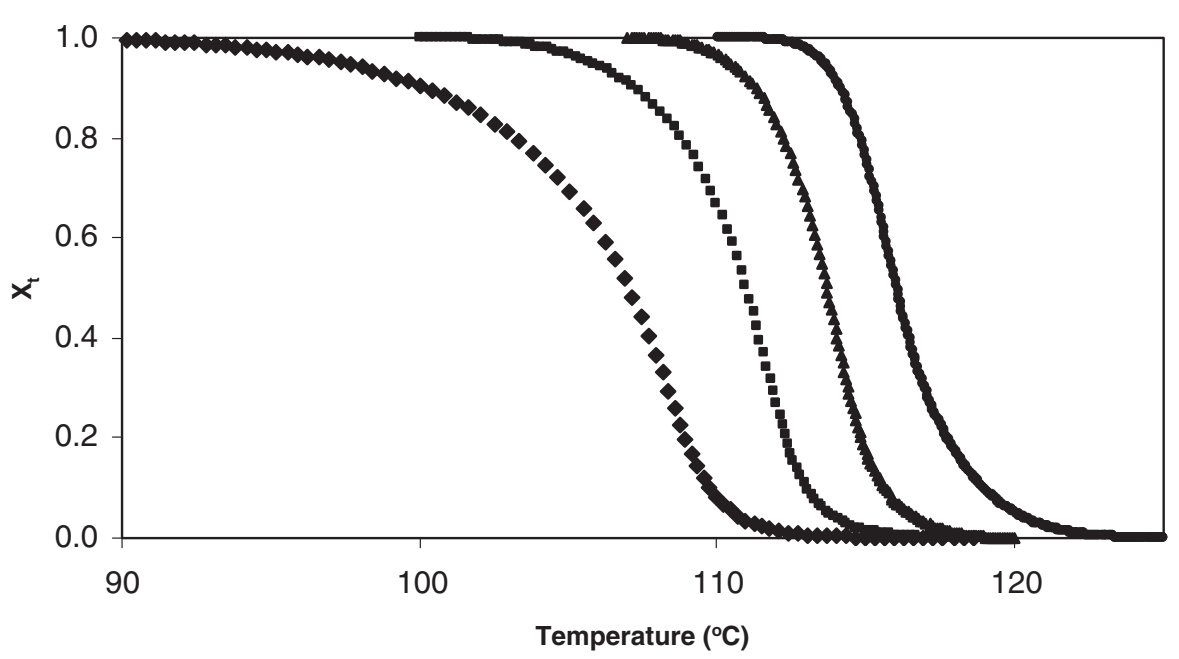

(a)

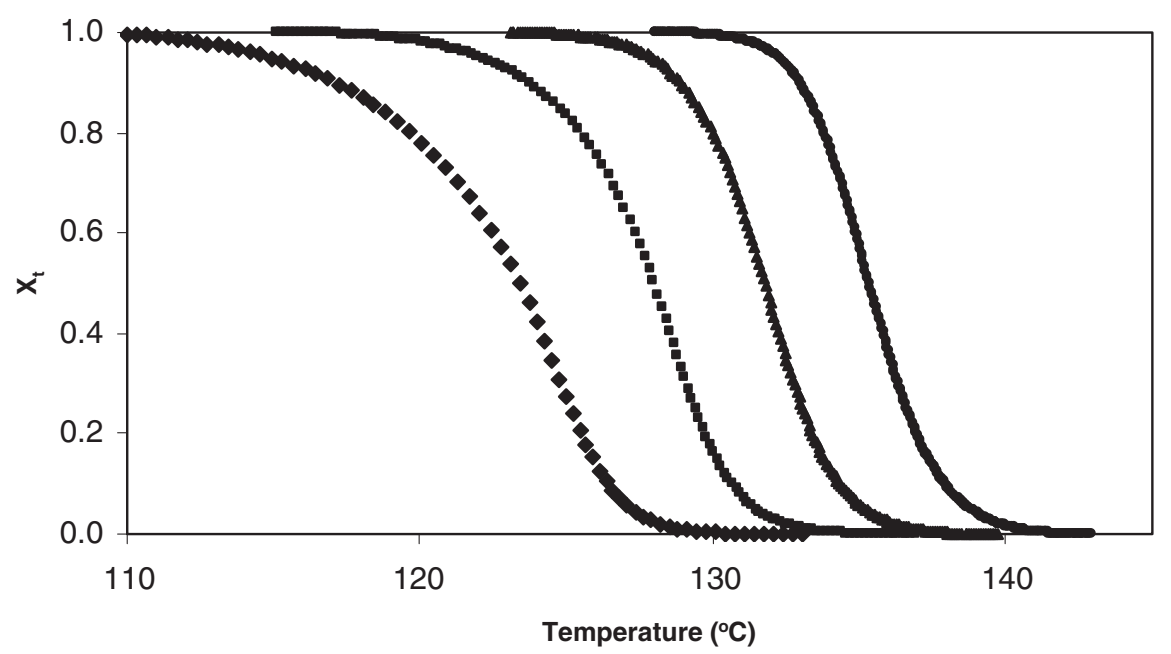

(b)

Figure 8. Relative crystallinity of (a) and (b) $\mathrm{PP}\left(X_{T}\right) \mathrm{PP} / \mathrm{PP}-\mathrm{g}-\mathrm{MA}(5) / \mathrm{GO}(1) / \mathrm{G}(4)\left(X_{T}\right)$ as function of temperature at cooling rates of: $(\bullet) 20^{\circ} \mathrm{C} / \min (\square) 10^{\circ} \mathrm{C} / \min (\boldsymbol{\Delta}) 5^{\circ} \mathrm{C} / \min (\bullet) 2.5^{\circ} \mathrm{C} / \mathrm{min}$.

$$
\ln \left[-\ln \left(1-X_{t}\right)\right]=\ln \chi-m \ln \varphi
$$

In eqs 5 and $6, X_{T}$ is the relative crystallinity in relation to the final crystallinity of the material crystallized at temperature $T, \varphi$ is the constant cooling rate, $m$ is the Ozawa exponent, which depends on the nucleation density and the spherulitic radial growth rate for both instantaneous and sporadic nucleation and $\chi$ is the cooling crystallization function.

Liu et al. combined ${ }^{45}$ both models by Ozawa and Avrami from eqs 4 and 6 to produce another crystallization kinetic model shown in eq 7.

$$
\ln \varphi=\ln F(T)-a \ln t
$$

In eq $7, F(T)=[\chi / k]^{1 / m}$ and $a=n / m$. Both parameters are determined by plotting $\ln \varphi$ against $\ln t$. The overall non-isothermal crystallization kinetics of PP and its composites with graphite was studied using eqs 6 and 7 .

In order to use the above mentioned models, the $X_{T}$ is calculated from the relationship of heat flow with the temperature, $T$ :

$$
X_{T}=\frac{\int_{T_{o}}^{T}\left(d H_{c} / d T\right) d T}{\int_{T_{o}}^{T_{\infty}}\left(d H_{c} / d T\right) d T}
$$

The amorphous fractions $\left(1-X_{T}\right)$ of the PP phase of $\mathrm{PP} / \mathrm{PP}-\mathrm{g}-\mathrm{MA}(5) / \mathrm{GO}(1) / \mathrm{G}(4)$ nanocomposites were calculated from the DSC cooling curves and plotted against $T$ for different cooling rates. The plots drawn for pure PP and for PP/PP-g-MA/GO/G nanocomposites are shown in Figures $8 \mathrm{a}$ and $8 \mathrm{~b}$, respectively. The Ozawa plots were obtained by plotting the double logarithm of the amorphous fractions of PP against the logarithm of the cooling rate for a set 


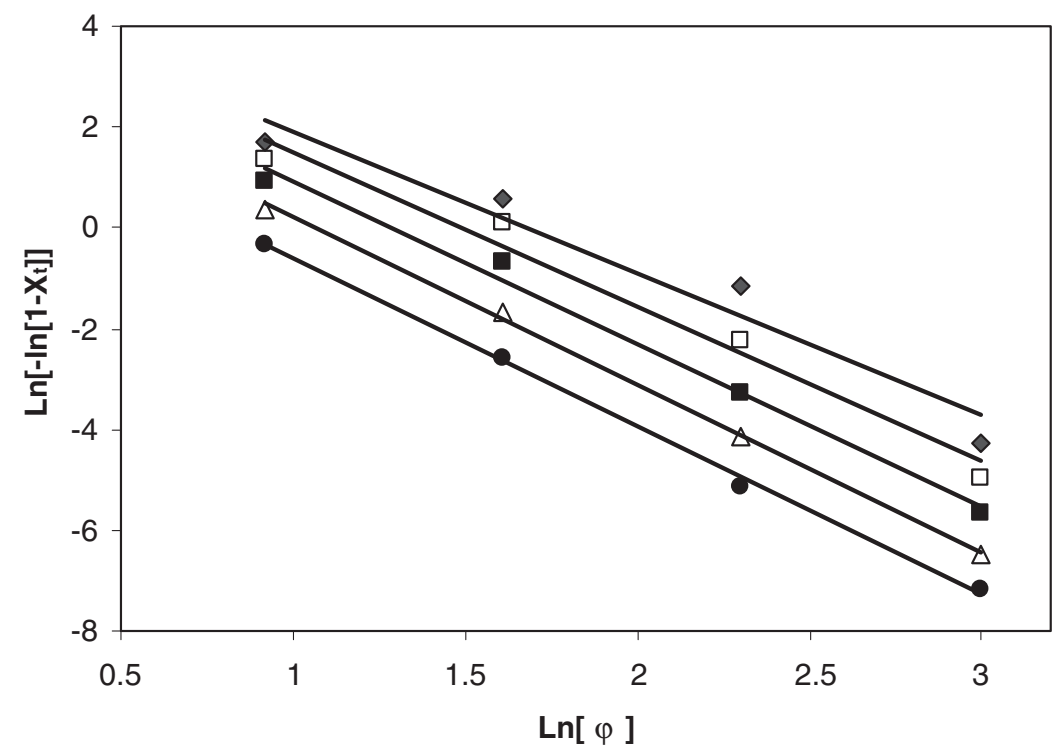

(a)

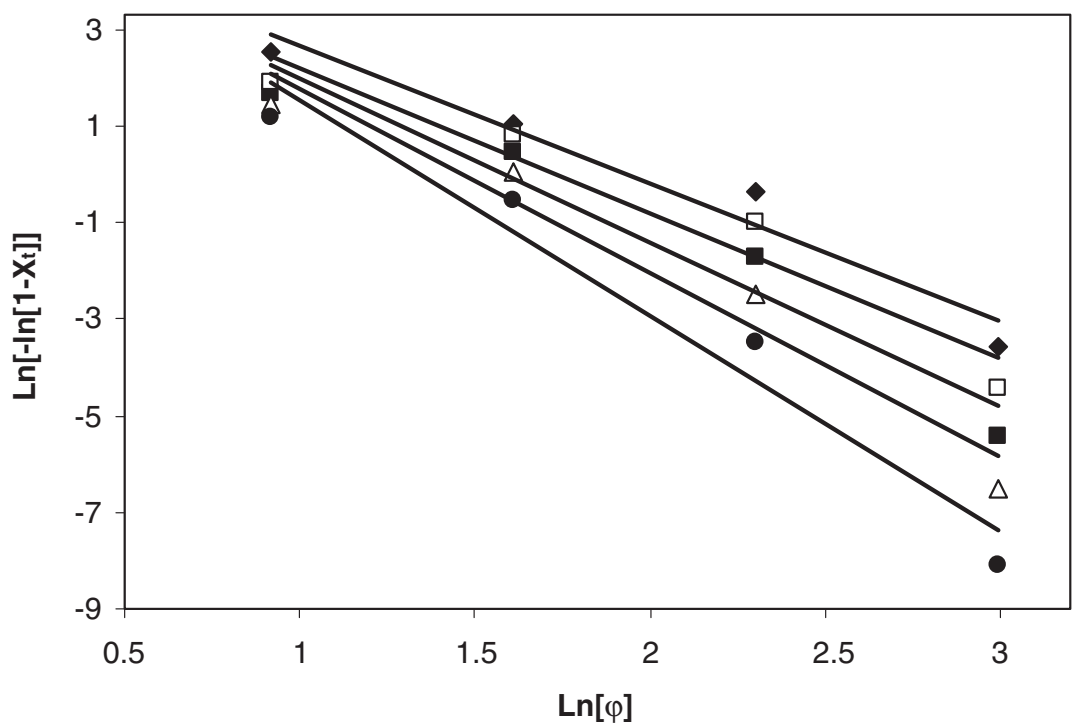

(b)

Figure 9. Ozawa plots for non-isothermal crystallization of (a) PP at: $112{ }^{\circ} \mathrm{C}(\bullet), 113^{\circ} \mathrm{C}(\square), 114^{\circ} \mathrm{C}(\square), 115^{\circ} \mathrm{C}(\triangle), 116^{\circ} \mathrm{C}(\bullet)$, and (b) $\mathrm{PP} / \mathrm{PP}-\mathrm{g}-\mathrm{MA}(5) / \mathrm{GO}(1) / \mathrm{G}(4)$ at: $128^{\circ} \mathrm{C}(\bullet), 129^{\circ} \mathrm{C}(\square), 130^{\circ} \mathrm{C}(\boldsymbol{\square}), 131^{\circ} \mathrm{C}(\triangle), 132^{\circ} \mathrm{C}(\bullet)$.

of temperatures selected in the early stages of crystallization as shown in Figures 9a and 9b. The onset of crystallization at $20^{\circ} \mathrm{C} / \mathrm{min}$ was used as a reference temperature for both materials.

Each series of points was modeled with a least square fitted linear relationship. The Ozawa exponent, $m$, was obtained from the slope of the Ozawa plots and the cooling crystallization function, $\chi$, was obtained from the intercept of the Ozawa plots, which represents the rate of non-isothermal crystallization. Both parameters were listed in Table III. PP gives a value in the range of 2.8-3.3, suggesting that the nucleated process leads to a spherulitic growth with thermal nucleation. ${ }^{22}$ The values of $m$ were larger for the PP nanocomposites which is consistent with PP crystalli-
Table III. Ozawa model parameters for non-isothermal crystallization of PP and PP/PP-g-MA(5)/GO(1)/G(4)

\begin{tabular}{lccr}
\hline & $T\left({ }^{\circ} \mathrm{C}\right)$ & $m$ & $\chi$ \\
\hline PP & 112 & 2.8 & 116 \\
& 113 & 3.1 & 97 \\
& 114 & 3.2 & 62 \\
& 115 & 3.3 & 34 \\
& 116 & 3.3 & 15 \\
\hline PP/PP-g-MA/GO/G & 128 & 2.9 & 237 \\
& 129 & 3.0 & 181 \\
& 130 & 3.4 & 215 \\
& 131 & 3.9 & 260 \\
& 132 & 4.5 & 392 \\
\hline
\end{tabular}




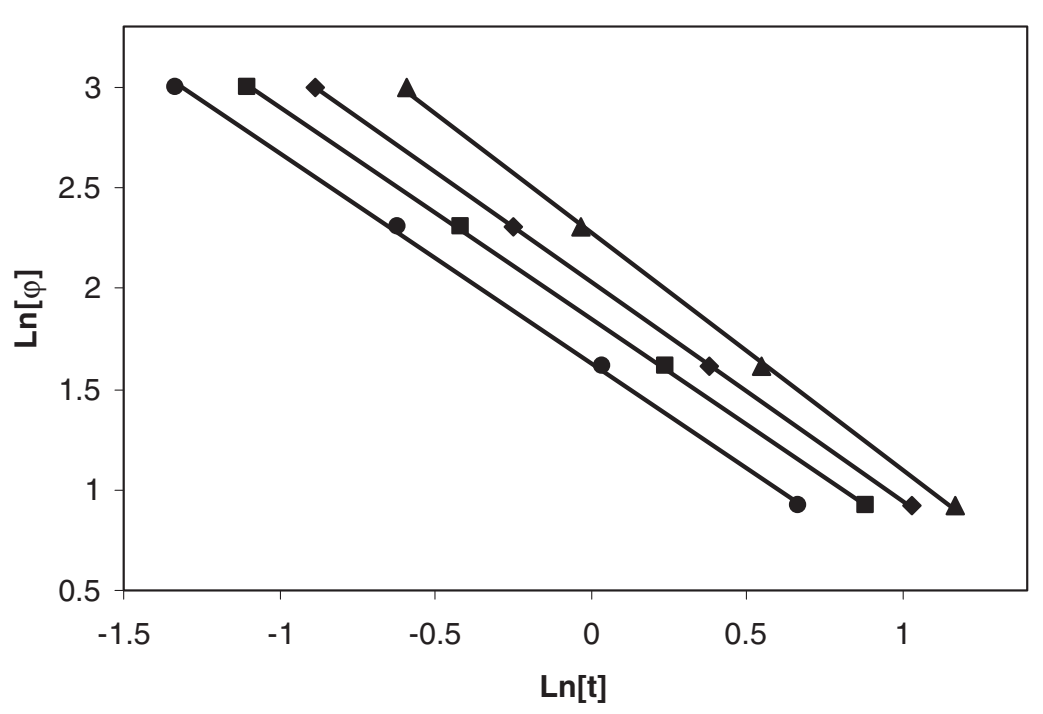

Figure 10. Liu et al. plots for non-isothermal crystallization of PP/PP-g-MA(5)/GO(1)/G(4) at a relative crystallinity of: $0.2(\bullet)$, $0.4(\mathbf{\square}), 0.6(\bullet)$ and $0.8(\boldsymbol{\Delta})$.

zation at higher temperature ${ }^{27,41}$ and crystallization with a nano-scale reinforcement. ${ }^{27}$ This finding shows that the type of nucleation and the geometry of the crystal growth markedly change in the presence of graphite. Those findings are further supported by SEM results of Figures $5 \mathrm{a}, 5 \mathrm{~b}$ and $5 \mathrm{c}$ and the previously reported XRD data. ${ }^{18}$

The intercept of the Ozawa plots gives the cooling crystallization function, $\chi$, which represents the rate of non-isothermal crystallization. The values of $\chi$ for PP, in Table III, are in good agreement with those reported in the literature. ${ }^{24-29}$ The $\chi$ values were higher for the PP nanocomposites indicating that the PP crystallization is faster with graphite. The values measured for the PP in PP nanocomposites are of the same order of magnitude as those obtained for PP/clay ${ }^{25,26,28,29}$ and $\mathrm{PP} / \mathrm{SiO}_{2}{ }^{27}$ nanocomposites, however no such values were found in the literature for $\mathrm{PP} / \mathrm{CNT}$ or $\mathrm{PP} /$ carbon black composites.

In Figure 10 crystallization data for the PP nanocomposite has been plotted using eq 7. The model parameters for $a$ and $F(T)$, obtained respectively from the slope and the intercept for both PP and PP nanocomposite, are shown in Table IV. The values for $a$ of the nanocomposite are comparable to those of neat $\mathrm{PP}$ as reported for $\mathrm{PP} / \mathrm{SiO}_{2},{ }^{27} \mathrm{PP} / \mathrm{cllay}^{29}$ and $\mathrm{PP} /$ CNT. ${ }^{39}$ The values for $F(T)$ are lower with the presence of nano-scale reinforcement but increase with crystallinity as reported for other nano-scale reinforcements. ${ }^{27,29,39}$ Lower $F(T)$ values are consistent with a higher rate of crystallization.

It can be concluded that the type of nucleation, growth and geometry of crystals markedly change in the presence of graphite particles with thicknesses in the nano-scale. This shift in the mechanism of crystal nucleation and growth leads to the development of a
Table IV. Liu et al. model parameters for non-isothermal crystallization of PP and PP/PP-g-MA(5)/GO(1)/G(4)

\begin{tabular}{lccc}
\hline & $X_{T}$ & $a$ & $F(T)$ \\
\hline PP & 0.2 & 1.0 & 5.6 \\
& 0.4 & 1.0 & 6.6 \\
& 0.6 & 1.1 & 7.7 \\
& 0.8 & 1.2 & 9.6 \\
\hline PP/PP-g-MA/GO/G & 0.2 & 1.0 & 5.1 \\
& 0.4 & 1.1 & 6.4 \\
& 0.6 & 1.1 & 7.6 \\
& 0.8 & 1.2 & 9.8 \\
\hline
\end{tabular}

fine grain micron-sized structure for the $\mathrm{PP} / \mathrm{G}$ nanocomposite, which improves the overall physical properties of the material.

\section{CONCLUSION}

Polypropylene (PP)/graphite (G) hybrid nanocomposites have been prepared by melt mixing using maleated PP (PP-g-MA) and graphite oxide (GO) as compatibilizing agents. Melt mixing was achieved using a Gelimat, a high-speed thermo-kinetic mixer specifically designed to handle difficult compounding and dispersion applications. The PP-g-MA and GO used as compatibilizers helped the dispersion of the graphite and improved flexural properties but more significantly the impact strength of the material. TEM micrographs showed a partial exfoliation of the graphite in the $\mathrm{PP} / \mathrm{PP}-\mathrm{g}-\mathrm{MA} / \mathrm{GO} / \mathrm{G}$ hybrid nanocomposites. SEM micrographs of etched nanocomposite samples showed a fine grain micron-sized structure, while pure PP was characterized by larger 20-30 micron-sized spherulites. Non-isothermal crystallization of PP and $\mathrm{PP} / \mathrm{PP}-\mathrm{g}-\mathrm{MA} / \mathrm{GO} / \mathrm{G}$ nanocomposites were investi- 
gated by differential scanning calorimetry (DSC). The crystallinity of the nanocomposite was up to $20 \%$ higher than for PP and the crystallization temperature was up to $15^{\circ} \mathrm{C}$ higher. Using the Kissinger model, the activation energy of crystallization of the nanocomposites was determined to be $237 \mathrm{KJ} \mathrm{mol}^{-1} v s$. $321 \mathrm{KJ} \mathrm{mol}^{-1}$ for the PP. Models by Ozawa and Liu et al. were used to analyze and describe the non-isothermal crystallization kinetics. The model parameters were comparable with those reported for PP with other nano-scale reinforcements. Overall, results indicate that the type of nucleation, growth and geometry of PP crystals markedly change in the presence of graphite particles with thicknesses in the nano-scale which improved the mechanical properties of the material.

Acknowledgment. The financial support provided by the NSERC is gratefully acknowledged. The authors would also like to thank Queen's Chemical Engineering department for the use of some equipment.

\section{REFERENCES}

1. "Polymer-Clay Nanocomposites," T. J. Pinnavaia and G. W. Beall, Ed., John Wiley \& Sons, Ltd, New York, 2001, chap. 2 .

2. M. Kawasumi, N. Hasegawa, M. Kato, A. Usuki, and A. Okada, Macromolecules, 30, 6333 (1997).

3. J. Heinemann, P. Reichert, R. Thomann, and R. Mulhaupt, Macromol. Rapid Commun., 20, 423 (1999).

4. A. Oya and Y. Kurokawa, J. Mater. Sci., 35, 1045 (2000).

5. E. P. Giannelis, Adv. Mater., 8, 29 (1996).

6. T. G. Gopakumar, J. A. Lee, M. Kontopoulou, and J. S. Parent, Polymer, 43, 5483 (2002).

7. Q. Guoqiang, J. W. Cho, and T. Lan, "Proc. of Polyolefins," Houston, TX 2001.

8. S. Hambir, N. Bulakh, P. Kodgire, R. Kalaonkar, and J. P. Jog, J. Appl. Polym. Sci., 39, 446 (2001).

9. F. Perrin-Sarazin, M.-T. Thon-That, M. N. Bureau, and J. Denault, Polymer, 46, 11624 (2005).

10. J.-J. Wu, T.-M. Wu, W.-Y. Chen, S.-J. Tsai, W.-F. Kuo, and G.-Y. Chang, J. Polym. Sci., Part B: Polym. Phys., 43, 3242 (2005).

11. K. H. Wang, M. H. Choi, C. M. Koo, Y. S. Choi, and I. J. Chung, Polymer, 42, 9819 (2001).

12. F. W. Uhl and C. A. Wilkie, Polym. Degrad. Stab., 76, 111 (2002)

13. J. W. Shen, X. M. Chen, and W. Y. Huang, J. Appl. Polym. Sci., 88, 1864 (2003).

14. Y. X. Pan, Z. Z. Yu, Y. C. Ou, and G. H. Hu, J. Polym. Sci., Part B: Polym. Phys., 38, 1626 (2000).

15. N. A. Kotov, I. Dekany, and J. H. Fendler, Adv. Mater, 8, 637 (1996).

16. W. Zheng, S. C. Wong, and H. J. Sue, Polymer, 43, 6767 (2002).
17. W. Zheng, X. Lu, and S. C. Wong, J. Appl. Polym. Sci., 91, 2781 (2004).

18. T. G. Gopakumar and D. J. Y. S. Pagé, Polym. Eng. Sci., 44, 1162 (2004).

19. S. Frenken, D. Lyons, and W. E. Baker, "49th SPE ANTEC," 1991, pp 40-45.

20. D. Lyons and W. E. Baker, Int. Polym. Process., 2, 136 (1990).

21. T. G. Gopakumar and D. J. Y. S. Pagé, J. Appl. Polym. Sci., 96, 1557 (2005).

22. L. Mandelkern, "Crystallization of polymers," McGrawHill, New York, 1964, pp 67-71.

23. B. Wunderlich, "Macromolecular physics," Academic Press, New York, 1973.

24. T. G. Gopakumar, R. S. Ghadage, S. Ponrathnam, and C. R. Rajan, Polymer, 38, 2209 (1997).

25. W. Xui, M. Ge, and P. J. He, J. Polym. Sci., Part B: Polym. Phys., 40, 408 (2002).

26. P. Maiti, P. H. Nam, M. Okamoto, N. Hasegawa, and A. Usuki, Macromolecules, 35, 2042 (2002).

27. J. Qian, P. He, and K. Nie, J. Appl. Polym. Sci., 91, 1013 (2004).

28. J.-D. He, M. K. Cheung, M.-S.Yang, and Z. Qi, J. Appl. Polym. Sci., 89, 3404 (2003).

29. W. Xu, G. Liang, H. Zhai, S. Tang, G. Hang, and W.-P. Pan, Eur. Polym. J., 39, 1467 (2003).

30. P. Svoboda, C. Zeng, H. Wang, L. Lee, and D. L. Tomasko, J. Appl. Polym. Sci., 85, 1562 (2002).

31. L. Valentini, J. Biagiotti, J. M. Kenny, and S. Santucci, J. Appl. Polym. Sci., 87, 708 (2003).

32. W. Zhu, G. Zhang, J. Yu, and G. Dai, J. Appl. Polym. Sci., 91, 431 (2004).

33. L. Valentini, J. Biagiotti, J. M. Kenny, and M. A. Lopez, J. Appl. Polym. Sci., 89, 2657 (2003).

34. A. Somwangthanaroj, E. C. Lee, and M. J. Solomon, Macromolecules, 36, 2333 (2003).

35. M. Mucha, J. Marszalek, and A. Fifrych, Polymer, 41, 4137 (2000).

36. B. P. Grady, F. Pompeo, R. L. Shambaugh, and D. E. Reasasco, J. Phys. Chem. B, 106, 5852 (2002).

37. A. R. Bhattacharyya, T. U. Sreekumar, T. Liu, S. Kumar, L. M. Ericson, R. H. Hauge, and R. E. Smalley, Polymer, 44, 2373 (2003).

38. L. Valentini, J. Biagiotti, J. M. Kenny, and S. Santucci, J. Appl. Polym. Sci., 87, 707 (2003).

39. W. Leelapornpisit, M.-T. Ton-That, F. Perrin-Sarazin, K. C. Cole, J. Denault, and B. Simard, J. Polym. Sci., Part B: Polym. Phys., 43, 2445 (2005).

40. J. Park, K. Eom, O. Kwon, and S. Woo, Microsc. Microanal., 7, 276 (2001).

41. M. Eder and A. Wlochowicz, Polymer, 24, 1593 (1983).

42. H. E. Kissinger, Anal. Chem., 29, 1702 (1957).

43. M. J. Avrami, Chem. Phys., 7, 1130 (1939).

44. T. Ozawa, Polymer, 12, 150 (1971).

45. T. Liu, Z. Mo, S. Wang, and H. Zhang, Polym. Eng. Sci., 37, 568 (1997). 